\title{
Socio-demographic and clinical factors contributing to smoking cessation among men: a four-year follow up study of the Korean Health Panel Survey
}

\author{
Joo Eun Lee ${ }^{1,2}$, Eun-Cheol Park ${ }^{2,3}$, Sung Youn Chun ${ }^{1,2}$, Hye Ki Park ${ }^{1,2}$ and Tae Hyun Kim², ${ }^{2,4^{*}}$
}

\begin{abstract}
Background: To examine factors contributing to smoking cessation among male smokers, we looked at how socio-demographic and clinical characteristics influence stopping smoking with passage of time.

Methods: Data from the Korea Health Panel during 2009-2012 were used. In 2009 a total of 2,941 smokers were followed up until 2012. Statistical analysis using a generalized linear mixed model was performed for all smokers, and a subgroup analysis was also performed to determine whether individual characteristics influence smoking cessation differently based on health condition.

Results: Male smokers who have married or graduated college or above were more likely to succeed in smoking cessation. Those with chronic disease(s) were also more likely to quit smoking than those without. Among those without chronic disease, higher education showed significant association with smoking cessation, however, being married or ever married showed significant association with smoking cessation among those with chronic disease.

Conclusions: The finding that higher education helped smokers without chronic disease succeed in smoking cessation suggests that a smoking cessation campaign should focus on those with lower education. In addition, quit smoking programs may be particularly helpful for male smokers with chronic disease(s) who have never married.
\end{abstract}

Keywords: Smoking cessation, Education, Marital status, Health status

Abbreviations: BMI, Body mass index; NHI, National Health Insurance; OECD, Organization for Economic Co-operation and Development; SES, Socioeconomic status

\section{Background}

Nearly 6 million people die prematurely from tobacco use every year, including those who are exposed to second-hand smoke [1]. Smoking is the greatest risk factor to health in Organization for Economic Cooperation and Development (OECD) countries. Many tobacco control policies (public awareness campaign, bans on advertising, increased tobacco tax, expanded ban on smoking in public places, and counseling for

\footnotetext{
* Correspondence: Thkim@yuhs.ac; tannykim74@gmail.com

${ }^{2}$ Institute of Health Services Research, Yonsei University College of Medicine, 50 Yonsei-ro, Seodaemun-gu, Seoul 120-752, Republic of Korea

${ }^{4}$ Department of Hospital Administration, Graduate School of Public Health, Yonsei University, 50 Yonsei-ro,Seodaemun-gu, Seoul 120-752, Republic of Korea

Full list of author information is available at the end of the article
}

smoking cessation) have been implemented with the aim of reducing smoking prevalence [2]. Although the smoking rate in South Korea decreased from $24.0 \%$ in 2006 to $23.2 \%$ in 2011, the male smoking rate in South Korea of $41.6 \%$ continues to be much higher than the average of OECD countries, with $25.7 \%$ in 2011. The gender gap in the adult population of smokers was particularly large in South Korea, one of the countries having the highest smoking prevalence in male and the lowest smoking prevalence in female. In addition, while the average smoking rates in OECD countries declined by $21 \%$ between 2000 and 2011, the smoking rate in South Korea over the same period decreased by $11 \%$ [3].

In 2015, the Korean government amended the 2003 National Health Enhancing Law and expanded smoke- 
free areas to include public places such as restaurants, cafes, and bars [4]. Furthermore, the government raised the cigarette tax in 2004 and 2015. Despite these efforts to reduce the smoking rate, South Korea's anti-smoking policy ranked $25^{\text {th }}$ among 27 OECD countries [5]. In addition, the government's policy has been criticized for achieving nothing besides increasing tax revenue and burdening low-income smokers [6]. Even though the overall smoking rates have decreased in South Korea, socioeconomic inequality in smoking remains high [7-9]. In this study, we attempted to examine indicators of socioeconomic status (SES), particularly education and other factors which affect smoking cessation in Korean men.

The perception of smoking risks and social support for smoking cessation may differ between men with chronic disease and those without chronic disease. The intention and ability to quit smoking are influenced by the knowledge, skills, and social support for doing so [10]. Although the Korean government has extended its antismoking policy, smoking cessation programs are mainly implemented by clinics and are not covered by National Health Insurance (NHI) [11]. Korea lacks an effective public campaign to reduce its smoking rate and disparity with regard to smoking cessation [12, 13]. The subgroup analyses on the basis of chronic disease, which may affect intention and ability to quit smoking, may help accurately identify the priority population. Using longitudinal data for 4 years, we attempted to investigate inequalities in smoking cessation success by SES.

\section{Methods}

We used the four waves of the Korea Health Panel (2009, 2010, 2011, 2012) conducted by the National Health Insurance Service and the Korea Institute for Health and Social Affairs. The Korea Health Panel Survey is a longitudinal survey based on a representative sample of the entire nation. The original sample was selected using a 2-stage cluster. For the baseline survey conducted in 2009, 18,724 individuals from 6,243 households were surveyed by well-trained interviewers using face-to-face method. This study used current smokers in Korean men, who account for most smokers in Korea. Females may not accurately report smoking status because of cultural reason [14]. Therefore we used 2,972 subjects who were current smokers among men aged 18 and older in 2009 as a baseline. Current smokers were defined as adults who reported having smoked at least 100 cigarettes in their lifetime and now smoking every day or some days at baseline $[15,16]$. The baseline was followed up with 2,609 subjects in 2010, 2,446 in 2011, and 2,255 in 2012. In total, 7,310 person-years were analyzed.
Outcome measure: short-term success at smoking cessation Short-term success at smoking cessation was assessed by surveying respondents who had not smoked for more than 6 months and were still not smoking [16]. This study excluded former smokers and newly added smokers in the baseline study population. Smoking status was measured by asking respondents "Have you smoked at least 100 cigarettes in your life time?" and if respondents answered "yes", they were asked "Do you now smoke every day, some days, or not at all?" [17] Those who reported having smoked at least 100 cigarettes in your lifetime and smoking at the time of the baseline survey in 2009 but not smoking at the time of the follow up survey were classified as former smokers. Smokers who reported smoking cigarettes every day or some days and former smokers who reported not smoking at the time of the survey but having not smoked for less than 6 months were considered current smokers. Incidence of smoking cessation for more than 6 months was measured at each follow up wave [18].

\section{Independent variables}

The primary independent variables were sociodemographic (SES and marital status) and clinical (chronic disease) factors. SES included education level, income level and employment status. Education level was divided into three categories: low (middle school or less), moderate (high school), and high (college or higher). Income level also divided into three categories. Employment status divided into two categories (yes or no). Marital status was coded as never married, married, and widowed/divorced/ separated. Chronic disease included the number of chronic diseases, cancers, and circulatory system diseases. The number of chronic diseases was asked, "How many chronic diseases do you have?" In addition, the list of chronic diseases was asked, "What kind of chronic disease do you have?" and "Have you been diagnosed with the disease by a physician?" We included cancer and circulatory system diseases which are major chronic diseases in Korea [19].

Covariates used as categorical variables were age (18-44, 45-64, 265), health insurance (NHI, Medical aid), residential area (Metropolitan area, Others), cancers (No, Yes), circulatory system diseases (No, Yes), body mass index (BMI) $(<23, \geq 23)$, and drinking frequency (Never, Monthly or less, 2 to 4 times a month, 2 to 3 times a week, 4 or more times a week) [20]. The proposed cutoff value for BMI in Asian populations was $23 \mathrm{~kg} / \mathrm{m}^{2}$ [21]. Independent variables collected at the time of each wave were used in the analysis.

\section{Statistical analysis}

Chi-square test was used for descriptive statistics. This study was conducted using a generalized linear mixed model using smoking cessation between 2010 and 2012 
as the dependent variable among smokers at the baseline in 2009. Excluding women, because the results of surveying women smokers may be underestimated, we focused on men aged 18 years and older at the time of the survey. To create a homogeneous group, we divided respondents by chronic disease and performed a subgroup analysis. SAS 9.4 was used for all analyses.

\section{Results}

The descriptive statistics in men stratified by smoking cessation for each wave are shown in Table 1. Total number of male smokers was 2,971 at the baseline. Of the initial study sample, 2,609 individuals were followed up in 2010, 2,446 in 2011, and 2,255 in 2012. Among respondents who were followed up from 2010 to 2012, respondents who reported smoking cessation for more than 6 months were $7.2 \%$ in 2010, $10.2 \%$ in 2011, and $12.5 \%$ in 2012. By age, smoking cessation was highest among men older than 65 years $(8.4 \%$ in $2009 ; 13.9 \%$, $p$-value $=0.0073$ in $2010 ; 20.8 \%, p$-value $<0.0001$ in 2012). A higher proportion of married men reported smoking cessation $(7.8 \%, p$-value $=0.0379$ in 2010; $10.9 \%, p$-value $=0.0706$ in $2011 ; 13.9 \%, p$-value $=$ 0.0008 in 2012). Those having no chronic disease had the lowest probability of smoking cessation $(6.2 \%, p$-value $=$ 0.0476 in 2010; $8.3 \%, p$-value $=0.0013$ in $2011 ; 9.2 \%$, $p$-value $<0.0001$ in 2012). In addition, men who were overweight or obese $(\mathrm{BMI} \geq 23) \quad(8.3 \%, p$-value $=$ 0.00213 in 2010; $11.2 \%, p$-value $=0.0944$ in 2011; $13.4 \%, p$-value $=0.1855$ in 2012) reported a higher proportion of smoking cessation.

Results of a generalized linear mixed model for smoking cessation in men are shown in Table 2. After adjusting for possible confounders, the table shows the association between marital status and smoking cessation. Smoking cessation was significantly higher for married men than for single men $(\mathrm{OR}=1.994,95 \% \mathrm{CI}=1.407-2.828)$. Men with college or above were more likely to stop smoking than those with middle school or below $(\mathrm{OR}=1.332$, $95 \% \mathrm{CI}=1.002-1.904)$. Higher income group also showed higher smoking cessation, but not significant $(\mathrm{OR}=1.039,95 \% \mathrm{CI}=0.805-1.340$ in men with middle income; $\mathrm{OR}=1.144,95 \% \mathrm{CI}=0.864-1.515$ in men with high income).

The number of chronic diseases showed a significant positive association with smoking cessation $(\mathrm{OR}=1.662$, $95 \% \mathrm{CI}=1.287-2.147$ in men with $1 \sim 2$ chronic diseases; $\mathrm{OR}=2.257,95 \% \mathrm{CI}=1.616-3.154$ in men with 3 or more chronic diseases). The table also shows the association between men who are overweight or obese and smoking cessation $(\mathrm{OR}=1.529,95 \% \mathrm{CI}=1.237-1.890)$. Men who drink alcohol 2 or more times a week were less likely to stop smoking than those who were not drinking $(\mathrm{OR}=0.664,95 \% \mathrm{CI}=0.475-0.927$ in 2 to 3 times a week; $\mathrm{OR}=0.499,95 \% \mathrm{CI}=0.338-0.738$ in 4 or more times a week).

Results of a generalized linear mixed model stratified by chronic disease are shown in Table 3 . In men without chronic disease, those older than 65 years were more likely to quit smoking cigarettes than those aged 18-44 years $(\mathrm{OR}=2.754,95 \% \mathrm{CI}=1.185-6.406)$. Smoking cessation in men without chronic disease was significantly higher for men with high school or above than for those with middle school or below $(\mathrm{OR}=2.133,95 \% \mathrm{CI}=$ $1.006-4.520$ in men with high school; $\mathrm{OR}=2.187,95 \%$ $\mathrm{CI}=1.005-4.763$ in men with college or above). Men who were overweight or obese $(B M I \geq 23)$ were more likely to stop smoking than those with normal weight $(\mathrm{OR}=1.597,95 \% \mathrm{CI}=1.161-2.196)$.

In terms of men with chronic disease, smoking cessation increased significantly between 2010 and 2012. In addition, smoking cessation in men with chronic disease was significantly higher for those who were married or widowed/divorced/separated than those who were never married $(\mathrm{OR}=2.963,95 \% \mathrm{CI}=1.571-5.590$ in married men; $\mathrm{OR}=2.523,95 \% \mathrm{CI}=1.124-5.665)$. The table also shows that men who were overweight or obese (BMI $\geq$ 23) were more likely to quit smoking than those with normal weight $(\mathrm{OR}=1.525,95 \% \mathrm{CI}=1.154-2.016)$.

\section{Discussion}

The objective of this study was to investigate the sociodemographic and clinical factors contributing to smoking cessation among male smokers in Korean society. We found that in general, among Korean male smokers, marital status, educational level, and chronic disease were associated with success in smoking cessation. However, income differences in smoking cessation were not found in our study. In terms of men without chronic disease, among overall male smokers, men with low education attainment showed a lower rate of smoking cessation than those with high education attainment. However, among men with chronic disease, inequality in smoking cessation success showed significant association with marital status, not with educational level.

Because of cultural differences in smoking, government policies, and the gender gap, the factors contributing to smoking cessation among Korean male smokers are different from those contributing to smoking cessation other counties. In Korea, there is an old saying. "Never be friends with a person who has quit smoking," which implies that successful ex-smokers are so bitter that it is hard to get along with them. Thus, Korean male smokers undoubtedly have some negative views on smoking cessation. Furthermore, the Korean government has a complicated relationship with the tobacco industry. The government control the profits from cigarette sales which are transferred to the public purse, but at the 
Table 1 Socio-demographic and clinical characteristics in male smokers between 2009 and 2012, by smoking cessation

\begin{tabular}{|c|c|c|c|c|c|c|c|c|c|c|c|c|c|}
\hline & \multirow{3}{*}{$\begin{array}{l}2009 \text { (baseline) } \\
\text { Smoking } \\
\text { N }\end{array}$} & \multicolumn{4}{|l|}{2010} & \multicolumn{4}{|l|}{2011} & \multicolumn{4}{|l|}{2012} \\
\hline & & \multicolumn{2}{|c|}{ Smoking } & \multicolumn{2}{|c|}{$\begin{array}{l}\text { Smoking } \\
\text { cessation }\end{array}$} & \multicolumn{2}{|c|}{ Smoking } & \multicolumn{2}{|c|}{$\begin{array}{l}\text { Smoking } \\
\text { cessation }\end{array}$} & \multicolumn{2}{|l|}{ Smoking } & \multicolumn{2}{|c|}{$\begin{array}{l}\text { Smoking } \\
\text { cessation }\end{array}$} \\
\hline & & $\bar{N}$ & (\%) & $\mathrm{N}$ & $(\%)$ & $\mathrm{N}$ & $(\%)$ & $\mathrm{N}$ & (\%) & $\mathrm{N}$ & $(\%)$ & $\mathrm{N}$ & $(\%)$ \\
\hline \multicolumn{14}{|l|}{ Age } \\
\hline $18-44$ & 1,436 & 1,158 & (93.4) & 82 & $(6.61)$ & $1044^{* *}$ & (91.6) & $96^{* *}$ & $(8.42)$ & $942^{* * *}$ & $(90.0)$ & $104^{* * *}$ & $(9.9)$ \\
\hline $45-64$ & 1,134 & 926 & (92.6) & 74 & $(7.40)$ & 841 & (89.0) & 104 & $(11.0)$ & 764 & (87.6) & 108 & (12.4) \\
\hline$\geq 65$ & 401 & 338 & (91.6) & 31 & $(8.40)$ & 311 & $(86.2)$ & 50 & $(13.9)$ & 267 & $(79.2)$ & 70 & (20.8) \\
\hline \multicolumn{14}{|l|}{ Marital status } \\
\hline Never married & 598 & $466^{*}$ & (95.5) & $22^{*}$ & $(4.51)$ & 410 & $(92.8)$ & 32 & $(7.2)$ & $383^{* * *}$ & (93.0) & $29^{* * *}$ & (7.04) \\
\hline Married & 2,216 & 1,830 & $(92.2)$ & 155 & $(7.81)$ & 1,671 & $(89.1)$ & 205 & $(10.9)$ & 1,486 & $(86.1)$ & 239 & (13.9) \\
\hline Widowed/ divorced/ separated & 157 & 126 & $(92.7)$ & 10 & $(7.35)$ & 115 & $(89.8)$ & 13 & $(10.2)$ & 104 & $(88.1)$ & 14 & $(11.9)$ \\
\hline \multicolumn{14}{|l|}{ Health insurance type } \\
\hline $\mathrm{NHI}$ & 2,868 & 2,334 & $(92.7)$ & 184 & $(7.31)$ & 2,111 & $(89.6)$ & 245 & $(10.4)$ & 1,898 & $(87.4)$ & 273 & $(12.6)$ \\
\hline Medical aid & 103 & 88 & $(96.7)$ & 3 & $(3.30)$ & 85 & $(94.4)$ & 5 & $(5.6)$ & 75 & (89.3) & 9 & $(10.7)$ \\
\hline \multicolumn{14}{|l|}{ Residential area } \\
\hline Metropolitan area & 1,329 & 1,064 & $(92.6)$ & 85 & $(7.40)$ & 968 & $(89.7)$ & 111 & $(10.3)$ & 869 & (88.3) & 115 & $(11.7)$ \\
\hline Others & 1,642 & 1,358 & (93.0) & 102 & $(6.99)$ & 1,228 & $(89.8)$ & 139 & $(10.2)$ & 1,104 & (86.9) & 167 & $(13.1)$ \\
\hline \multicolumn{14}{|l|}{ Education } \\
\hline$\leq$ Middle school & 675 & 565 & $(93.2)$ & 41 & $(6.77)$ & 522 & $(89.4)$ & 62 & $(10.6)$ & $459^{* *}$ & (83.5) & $91^{* *}$ & (16.6) \\
\hline High school & 1,146 & 951 & (93.5) & 66 & $(6.49)$ & 865 & $(91.1)$ & 85 & $(9.0)$ & 778 & $(89.2)$ & 94 & (10.8) \\
\hline$\geq$ College & 1,150 & 906 & (91.9) & 80 & $(8.11)$ & 809 & $(88.7)$ & 103 & $(11.3)$ & 736 & (88.4) & 97 & (11.6) \\
\hline \multicolumn{14}{|l|}{ Income level } \\
\hline Low & 982 & 830 & (94.4) & 49 & $(5.57)$ & 756 & (90.8) & 77 & $(9.2)$ & 687 & $(88.2)$ & 92 & (11.8) \\
\hline Middle & 1,010 & 813 & (92.6) & 65 & $(7.40)$ & 739 & $(89.7)$ & 85 & $(10.3)$ & 675 & (88.7) & 86 & (11.3) \\
\hline High & 979 & 779 & (91.4) & 73 & $(8.57)$ & 701 & $(88.9)$ & 88 & $(11.2)$ & 611 & (85.5) & 104 & (14.6) \\
\hline \multicolumn{14}{|l|}{ Job } \\
\hline No & 540 & 438 & (94.0) & 28 & $(6.01)$ & 399 & $(89.7)$ & 46 & $(10.3)$ & 360 & $(87.4)$ & 52 & (12.6) \\
\hline Yes & 2,431 & 1,984 & (92.6) & 159 & $(7.42)$ & 1,797 & (89.8) & 204 & $(10.2)$ & 1,613 & $(87.5)$ & 230 & (12.5) \\
\hline \multicolumn{14}{|l|}{ Number of chronic disease } \\
\hline 0 & 1,724 & $1397^{*}$ & (93.8) & $92^{*}$ & $(6.18)$ & $1259^{* *}$ & $(91.7)$ & $114^{* *}$ & $(8.30)$ & $1144^{* * *}$ & $(90.8)$ & $116^{* * *}$ & $(9.2)$ \\
\hline $1 \sim 2$ & 923 & 758 & (91.0) & 75 & $(9.00)$ & 692 & $(87.8)$ & 96 & $(12.2)$ & 621 & $(85.0)$ & 110 & $(15.1)$ \\
\hline$\geq 3$ & 324 & 267 & (93.0) & 20 & $(6.97)$ & 245 & $(86.0)$ & 40 & $(14.0)$ & 208 & $(78.8)$ & 56 & $(21.2)$ \\
\hline \multicolumn{14}{|l|}{ Cancers } \\
\hline No & 2,953 & 2,408 & $(92.9)$ & 185 & $(7.13)$ & 2,186 & $(89.9)$ & 246 & $(10.1)$ & 1,962 & (87.6) & 279 & $(12.5)$ \\
\hline Yes & 18 & 14 & (87.5) & 2 & $(12.50)$ & 10 & $(71.4)$ & 4 & $(28.6)$ & 11 & (78.6) & 3 & $(21.4)$ \\
\hline \multicolumn{14}{|l|}{ Disease of the circulatory system } \\
\hline No & 2,617 & 2,131 & $(92.8)$ & 165 & $(7.19)$ & 1,935 & $(90.1)$ & 213 & $(9.9)$ & 1,738 & $(88.0)$ & 237 & $(12.0)$ \\
\hline Yes & 354 & 291 & $(93.0)$ & 22 & $(7.03)$ & 261 & $(87.6)$ & 37 & $(12.4)$ & 235 & (83.9) & 45 & $(16.1)$ \\
\hline \multicolumn{14}{|l|}{ BMI } \\
\hline$<23$ & 1,392 & $1138^{*}$ & $(94.1)$ & $71^{*}$ & $(5.87)$ & 1,027 & $(90.9)$ & 103 & $(9.1)$ & 930 & $(88.5)$ & 121 & $(11.5)$ \\
\hline$\geq 23$ & 1,579 & 1,284 & (91.7) & 116 & (8.29) & 1,169 & (88.8) & 147 & $(11.2)$ & 1,043 & (86.6) & 161 & (13.4) \\
\hline
\end{tabular}


Table 1 Socio-demographic and clinical characteristics in male smokers between 2009 and 2012, by smoking cessation (Continued)

\begin{tabular}{|c|c|c|c|c|c|c|c|c|c|c|c|c|c|}
\hline \\
\hline \multicolumn{14}{|l|}{$\begin{array}{l}\text { Drinking trequency } \\
\text { Never }\end{array}$} \\
\hline Monthly or less & 439 & 371 & (95.9) & 16 & $(4.13)$ & 325 & (90.8) & 33 & $(9.2)$ & 309 & $(90.1)$ & 34 & (9.9) \\
\hline 2 to 4 times a month & 840 & 664 & $(91.7)$ & 60 & $(8.3)$ & 597 & (88.7) & 76 & (11.3) & 525 & $(86.0)$ & 86 & (14.0) \\
\hline 2 to 3 times a week & 916 & 752 & $(92.3)$ & 63 & $(7.7)$ & 701 & (91.5) & 65 & $(8.5)$ & 630 & $(89.9)$ & 71 & $(10.1)$ \\
\hline 4 or more times a week & 429 & 357 & $(92.5)$ & 29 & $(7.5)$ & 329 & (89.9) & 37 & $(10.1)$ & 297 & $(87.1)$ & 44 & $(12.9)$ \\
\hline Total & 2,971 & 2,422 & $(92.8)$ & 187 & $(7.17)$ & 2,196 & (89.8) & 250 & $(10.2)$ & 1,973 & (87.5) & 282 & (12.5) \\
\hline
\end{tabular}

${ }^{*} p<0.001,{ }^{* *} p<0.01,{ }^{* * *} p<0.05$

$P$-values are for chi-square tests

same time, the government's public role is to improve public health and it also has a social responsibility to do the same [12]. The government's policy has been criticized for filling the tax deficit with the extra tobacco tax and achieving nothing besides increasing tax revenue [6]. In addition, the gender gap in smoking rates is particularly pronounced in Korea [3]. Therefore, wellstudied factors relevant to Korean society are necessary to effectively reduce its smoking rates and the disparity in smoking cessation.

A low educational level is a well-known factor associated with smoking [22-24]. With regard to education, this study showed that a high level of education was related to success in quitting smoking among Korean male smokers. In addition, smoking cessation is a preventive approach rather than a treatment for men without chronic disease, thus education is an important factor, particularly for them.

Marital status was an important factor in smoking cessation among Korean men, especially for those with chronic disease [25]. Smoking cessation showed a positive association with being both married and divorced/ widowed/separated [26]. This result might indicate that in Korea, married men with chronic disease receive more social support from their spouse or other family members than never married men with chronic disease in Korea. Korean society has a unique medical culture, wherein most caregivers of patients are family members. Therefore, family support may greatly enhance smoking cessation, especially in the Korean family culture. In addition, in Korea, smoking cessation programs are primarily implemented by clinics and are not free of charge. Therefore, men with chronic disease may have more opportunities to receive advice from health professionals than those without chronic disease even those with a low educational level. Therefore, in Korean society, in the case of men with chronic disease, marital status could be a better predictor of smoking cessation than education.

In the current study, smoking cessation success in Korean male smokers was significantly associated with educational level but not with household income. Many studies conducted in the United States and Europe have shown the association between smoking cessation and income $[27,28]$. Contrary to these results, some studies have shown that inequalities in smoking were clearer with education than current income $[29,30]$. Because of cultural differences regarding smoking, tobacco control policies, and inequality in smoking rates, the results of these studies are difficult to generalize to other East Asian countries. Another possible explanation for the inequality in smoking cessation is the Korean government's 2004 tobacco price increase enforcement [31, 32]. According to recent studies, effect on inequalities can differ depending on the type of tobacco control policies [33]. Tobacco price increase was likely to reduce smoking among low-income people [34]. Therefore, raising tobacco taxes had mainly a positive equity impact which reduced inequalities [35].

There are several limitations associated with this study. First, smoking cessation was measured by selfreported data without biological validation. The limitation of this survey method may result in under-reporting of smoking. Second, this study has the difficulty in generalising the results beyond South Korean male smokers. Because this study included only male smokers aged 18 and older at the baseline, differences could not be determined according to gender. Self-reported smoking prevalence in women was too low to analyze, thus women were not included in this study. Third, the data used in this study provide no information on nicotine dependence, sophisticated measure of smoking behavior, and adherence to smoking cessation treatment. However, it includes duration of smoking cessation, which makes measurement of success of smoking cessation possible. Fourth, although we used panel data, we suggest the need for caution in interpreting the results of this study. The analysis proves the association but not causality.

However, this study has several strengths. A more refined measure of smoking cessation was used in this study compared with the previous studies, with questions on never/current/former smoking and length of time since smoking cessation. Most studies defined smoking cessation without the duration of smoking cessation $[26,36]$. In 
Table 2 A generalized linear mixed model: association between participant's characteristics and smoking cessation in men

\begin{tabular}{l} 
Smoking cessation \\
\hline $\mathrm{OR} \quad 95 \% \mathrm{Cl}$
\end{tabular}

\begin{tabular}{l} 
Age (years) \\
$18-44$ \\
$45-64$ \\
$\geq 65$ \\
Marital status \\
Never married \\
Married \\
Widowed/ divorced/ separated \\
Health insurance type \\
NHI \\
Medical aid \\
Residential area \\
Metropolitan area \\
Others \\
Education \\
$\leq$ Middle school \\
High school \\
$\geq$ College \\
Income level \\
Low \\
Middle \\
Hobh \\
No \\
\hline Mes
\end{tabular}

\subsection{0}

1.058

1.422

1.000

1.994

1.436

1.000

0.822

1.000

0.978

1.000

1.124

1.332

1.000

1.039

1.144

1.000

1.024

The number of chronic diseases

$$
0
$$$$
1 \sim 2
$$$$
\geq 3
$$

\section{Cancers}

$$
\begin{aligned}
& \text { No } \\
& \text { Yes }
\end{aligned}
$$

Circulatory system diseases

$$
\begin{aligned}
& \text { No } \\
& \text { Yes }
\end{aligned}
$$$$
\text { BMI }
$$$$
<23
$$$$
\geq 23
$$

Drinking frequency

Never

$0.799 \quad 1.399$

1.407

2.828

2.578 addition, two potentially separate stages are included in the process of smoking cessation. The important factors of quit attempt and success in quit attempt may be different. This study focused on factors related to success in smoking cessation. However, in most previous studies these two stages were not separated. Another strength of this study relates to its relatively large sample size and the longitudinal nature of the data providing a good indicator of successful smoking cessation. In addition, excluding respondents who had already quit smoking in the baseline, we tried to control confounders that had existed before the observation. Finally, we used a refined measure of chronic disease as the number of chronic diseases, prevalence of cancers, and prevalence of circulatory system diseases. Many studies on the effects of smoking cessation on chronic disease have been reported. However, in most studies on the association between smoking cessation and SES, chronic disease was not controlled [18, 37, 38].

\section{Conclusion}

The results of this study showed that there are differences in possibility of smoking cessation success according to marital status, educational level, and chronic disease. The number of chronic diseases influences immediate health needs for treatment, so that smoking cessation can differ between men with chronic disease and those without chronic disease. After stratifying for chronic disease, educational level was a crucial factor of smoking cessation, which is a preventive approach for men without chronic disease. However, among men with chronic disease, marital status was an important social support for smoking cessation that is needed immediately for treatment of chronic disease. However, more studies on the differences of the impact of education and marital status by chronic disease are needed. In addition, differences in smoking cessation may add to inequality in smoking rate. Therefore, we suggest that effective intervention for the disadvantaged group (unmarried smokers and low educated smokers) should be a priority of tobacco control policies to improve smoking cessation. 
Table 3 A generalized linear mixed model: association between participant's characteristics and smoking cessation by chronic disease in men

\begin{tabular}{|c|c|c|c|c|c|c|}
\hline & \multicolumn{6}{|c|}{ Smoking cessation } \\
\hline & \multicolumn{3}{|c|}{ Having no chronic disease } & \multicolumn{3}{|c|}{ Having chronic disease } \\
\hline & $\overline{\mathrm{OR}}$ & $95 \% \mathrm{C}$ & & $\overline{\mathrm{OR}}$ & $95 \% C$ & \\
\hline \multicolumn{7}{|l|}{ Age (years) } \\
\hline $18-44$ & 1.000 & & & 1.000 & & \\
\hline $45-64$ & 1.244 & 0.845 & 1.832 & 0.964 & 0.650 & 1.429 \\
\hline$\geq 65$ & 2.754 & 1.184 & 6.406 & 1.223 & 0.740 & 2.002 \\
\hline \multicolumn{7}{|l|}{ Marital status } \\
\hline Never married & 1.000 & & & 1.000 & & \\
\hline Married & 1.688 & 1.080 & 2.576 & 2.963 & 1.571 & 5.590 \\
\hline Widowed/ divorced/ separated & 0.611 & 0.176 & 2.125 & 2.523 & 1.124 & 5.665 \\
\hline \multicolumn{7}{|l|}{ Health insurance type } \\
\hline $\mathrm{NHI}$ & 1.000 & & & 1.000 & & \\
\hline Medical aid & 0.443 & 0.051 & 3.867 & 0.908 & 0.487 & 1.693 \\
\hline \multicolumn{7}{|l|}{ Residential area } \\
\hline Metropolitan area & 1.000 & & & 1.000 & & \\
\hline Others & 0.938 & 0.682 & 1.288 & 1.004 & 0.752 & 1.340 \\
\hline \multicolumn{7}{|l|}{ Education } \\
\hline$\leq$ Middle school & 1.000 & & & 1.000 & & \\
\hline High school & 2.133 & 1.006 & 4.520 & 0.923 & 0.635 & 1.341 \\
\hline$\geq$ College & 2.187 & 1.005 & 4.763 & 1.243 & 0.810 & 1.907 \\
\hline \multicolumn{7}{|l|}{ Income level } \\
\hline Low & 1.000 & & & 1.000 & & \\
\hline Middle & 0.911 & 0.605 & 1.373 & 1.136 & 0.823 & 1.568 \\
\hline High & 1.178 & 0.775 & 1.789 & 1.082 & 0.743 & 1.577 \\
\hline \multicolumn{7}{|l|}{ Job } \\
\hline No & 1.000 & & & 1.000 & & \\
\hline Yes & 1.262 & 0.788 & 2.002 & 0.898 & 0.640 & 1.262 \\
\hline \multicolumn{7}{|l|}{ BMI } \\
\hline$<23$ & 1.000 & & & 1.000 & & \\
\hline$\geq 23$ & 1.597 & 1.161 & 2.196 & 1.525 & 1.154 & 2.016 \\
\hline \multicolumn{7}{|l|}{ Drinking frequency } \\
\hline Never & 1.000 & & & 1.000 & & \\
\hline Monthly or less & 0.971 & 0.558 & 1.689 & 1.192 & 0.787 & 1.804 \\
\hline 2 to 4 times a month & 0.934 & 0.552 & 1.581 & 0.846 & 0.562 & 1.274 \\
\hline 2 to 3 times a week & 0.455 & 0.259 & 0.800 & 0.795 & 0.529 & 1.196 \\
\hline 4 or more times a week & 0.381 & 0.189 & 0.766 & 0.537 & 0.337 & 0.856 \\
\hline \multicolumn{7}{|l|}{ Year } \\
\hline 2010 & 0.812 & 0.588 & 1.120 & 0.435 & 0.330 & 0.572 \\
\hline 2011 & 0.901 & 0.653 & 1.242 & 0.713 & 0.556 & 0.913 \\
\hline 2012 & 1.000 & & & 1.000 & & \\
\hline
\end{tabular}




\section{Acknowledgements}

Korea Health Panel provided national level of data.

\section{Funding}

This research received no specific grant from any funding agency in the public, commercial or not-for-profit sectors.

\section{Availability of data and materials}

The data supporting this article is available in https://www.khp.re.kr:444/.

\section{Authors' contribution}

JEL designed the study, carried out the statistical analysis, and wrote the paper. E-CP, SYC and HKP provided important comments for the method and discussion. THK directed this study as corresponding author. All authors read and approved the final manuscript.

\section{Competing interests}

The authors declare that they have no competing interests.

\section{Consent for publication}

Not applicable.

\section{Ethics approval and consent to participate}

Not applicable. We used public and national open data.

\section{Author details \\ 'Department of Public Health, Yonsei University College of Medicine, 50 Yonsei-ro, Seodaemun-gu, Seoul 120-752, Republic of Korea. ${ }^{2}$ Institute of Health Services Research, Yonsei University College of Medicine, 50 Yonsei-ro, Seodaemun-gu, Seoul 120-752, Republic of Korea. ${ }^{3}$ Department of Preventive Medicine, Yonsei University College of Medicine, 50 Yonsei-ro, Seodaemun-gu, Seoul 120-752, Republic of Korea. ${ }^{4}$ Department of Hospital Administration, Graduate School of Public Health, Yonsei University, 50 Yonsei-ro,Seodaemun-gu, Seoul 120-752, Republic of Korea.}

\section{Received: 24 March 2016 Accepted: 24 August 2016}

\section{Published online: 31 August 2016}

\section{References}

1. World Health Organization (WHO). WHO report on the global tobacco epidemic, 2013. 2013.

2. Schaap M, Kunst A. Monitoring of socio-economic inequalities in smoking: learning from the experiences of recent scientific studies. Public Health. 2009:123(2):103-9.

3. Organization for Economic Cooperation and Development (OECD). OECD factbook 2014. 2014

4. World Health Organization Framework Convention on Tobacco Control (WHO FCTC). Republic of Korea: smoking ban extended. In: WHO framework convention on tobacco control. 2015.

5. Jeong Y-h, Ko SJ. Composite indicator for tobacco control policy in Korea. Health-Welf Policy Forum. 2014;211(5):70-84

6. Kim J-Y. Cigarette tax increase unjust, says lawmaker. Seoul: Korea Joongang Daily; 2015.

7. Kim H. Socioeconomic inequality and its trends in cigarette smoking in South Korea, 1998-2005. Health Soc Welf Rev. 2007;27(2):25-43.

8. Khang $\mathrm{Y}-\mathrm{H}, \mathrm{Cho} \mathrm{H}-\mathrm{J}$. Socioeconomic inequality in cigarette smoking: trends by gender, age, and socioeconomic position in South Korea, 1989-2003. Prev Med. 2006;42(6):415-22.

9. Khang $\mathrm{Y}-\mathrm{H}$, Yun $\mathrm{S}-\mathrm{C}, \mathrm{Cho} \mathrm{H}-\mathrm{J}$, Jung-Choi K. The impact of governmental antismoking policy on socioeconomic disparities in cigarette smoking in South Korea. Nicotine Tob Res. 2009;11:262-9. doi:10.1093/ntr/ntn036.

10. Ma GX, Fang C, Shive SE, Su X, Toubbeh JI, Miller S, Tan Y. A culturally enhanced smoking cessation study among Chinese and Korean Smokers. Int Electron J Health Educ. 2005;8:1-10.

11. OECD. OECD reviews of health care quality. Korea: OECD; 2012. p. 154

12. Kang HY, Kim H, Park T-K, Jee SH, Nam CM, Park HW. Economic burden of smoking in Korea. Tob Control. 2003;12(1):37-44.

13. Kim B. Workplace smoking ban policy and smoking behavior. J Prev Med Public Health. 2009;42(5):293-7.
14. Park MB, Kim C-B, Nam EW, Hong KS. Does South Korea have hidden female smokers: discrepancies in smoking rates between self-reports and urinary cotinine level. BMC Women's Health. 2014;14(1):1.

15. Hyland A, Borland R, Li Q, Yong HH, McNeill A, Fong GT, O'Connor RJ, Cummings K. Individual-level predictors of cessation behaviours among participants in the International Tobacco Control (ITC) Four Country Survey. Tob Control. 2006;15 suppl 3:iii83-94.

16. Centers for Disease Control Prevention (CDC). Quitting smoking among adults-United States, 2001-2010. In: Morbidity and Mortality Weekly Report (MMWR), vol. 60. 2011. p. 1513-9.

17. Blanco L, Garcia R, Perez-Stable EJ, White MM, Messer K, Pierce JP, Trinidad DR. National trends in smoking behaviors among Mexican, Puerto Rican, and Cuban men and women in the United States. Am J Public Health. 2014 104(5):896-903.

18. Reid JL, Hammond D, Boudreau C, Fong GT, Siahpush M. Socioeconomic disparities in quit intentions, quit attempts, and smoking abstinence among smokers in four western countries: findings from the International Tobacco Control Four Country Survey. Nicotine Tob Res. 2010;12 suppl 1:S20-33.

19. Korea Center for Disease Control and Prevention (KCDC). Prevention and management of major chronic diseases. In: Korea Center for Disease Control and Prevention. 2015.

20. Kim C-G, Kim JS, Jung J-G, Kim S-S, Yoon S-J, Suh H-S. Reliability and validity of alcohol use disorder dentification test-korean revised version for screening at-risk drinking and alcohol use disorders. Korean J Fam Med. 2014:35(1):2-10.

21. Jih J, Mukherjea A, Vittinghoff E, Nguyen TT, Tsoh JY, Fukuoka Y, Bender MS, Tseng W, Kanaya AM. Using appropriate body mass index cut points for overweight and obesity among Asian Americans. Prev Med. 2014;65:1-6.

22. Huisman M, Kunst A, Mackenbach J. Educational inequalities in smoking among men and women aged 16 years and older in 11 European countries. Tob Control. 2005;14(2):106-13.

23. Giskes K, Kunst AE, Benach J, Borrell C, Costa G, Dahl E, Dalstra JA, Federico B, Helmert U, Judge K. Trends in smoking behaviour between 1985 and 2000 in nine European countries by education. J Epidemiol Community Health. 2005;59(5):395-401.

24. Federico B, Costa G, Ricciardi W, Kunst AE. Educational inequalities in smoking cessation trends in Italy, 1982-2002. Tob Control. 2009;18(5):393-8.

25. Cho H-J, Khang Y-H, Jun H-J, Kawachi I. Marital status and smoking in Korea: the influence of gender and age. Soc Sci Med. 2008;66(3):609-19.

26. Broms U, Silventoinen K, Lahelma E, Koskenvuo M, Kaprio J. Smoking cessation by socioeconomic status and marital status: the contribution of smoking behavior and family background. Nicotine Tob Res. 2004;6(3):447-55

27. Hiscock R, Judge $K$, Bauld L. Social inequalities in quitting smoking: what factors mediate the relationship between socioeconomic position and smoking cessation? J Public Health. 2010;33:39-47. doi:10.1093/pubmed/fdq097.

28. Fagan P, Shavers V, Lawrence D, Gibson JT, Ponder P. Cigarette smoking and quitting behaviors among unemployed adults in the United States. Nicotine Tob Res. 2007:9(2):241-8.

29. Huisman M, Kunst AE, Mackenbach JP. Inequalities in the prevalence of smoking in the European Union: comparing education and income. Prev Med. 2005;40(6):756-64.

30. Fernandez E, Schiaffino A, Borrell C, Benach J, Ariza C, Ramon JM, Twose J, Nebot M, Kunst A. Social class, education, and smoking cessation: Long-term follow-up of patients treated at a smoking cessation unit. Nicotine Tob Res. 2006;8(1):29-36.

31. Song TM, Lee J. A multilevel model analysis on the determinants of smoking cessation success rates. Korean J Health Educ Promot. 2013;30(1):53-64.

32. Kim WN, Suh JH, Kim YJ. The effect of price increase on tobacco consumption. Popul Assoc Korea. 2006:29(2):195-213.

33. Brown T, Platt $S$, Amos A. Equity impact of European individual-level smoking cessation interventions to reduce smoking in adults: a systematic review. Eur J Public Health. 2014;24:551-6. doi:10.1093/eurpub/cku065.

34. Hiscock R, Bauld L, Amos A, Fidler JA, Munafo M. Socioeconomic status and smoking: a review. Ann N Y Acad Sci. 2012;1248(1):107-23.

35. Hill S, Amos A, Clifford D, Platt S. Impact of tobacco control interventions on socioeconomic inequalities in smoking: review of the evidence. Tob Control. 2014:23(e2):e89-97.

36. Bosdriesz JR, Willemsen MC, Stronks K, Kunst AE. Socioeconomic inequalities in smoking cessation in 11 European countries from 1987 to 2012. J Epidemiol Community Health. 2015. doi:10.1136/jech-2014-205171. 
37. Honjo K, Tsutsumi A, Kawachi I, Kawakami N. What accounts for the relationship between social class and smoking cessation? Results of a path analysis. Soc Sci Med. 2006;62(2):317-28.

38. Hiscock $R$, Judge $K$, Bauld L. Social inequalities in quitting smoking: what factors mediate the relationship between socioeconomic position and smoking cessation? J Public Health (Oxf). 2011;33(1):39-47.

Submit your next manuscript to BioMed Central and we will help you at every step:

- We accept pre-submission inquiries

- Our selector tool helps you to find the most relevant journal

- We provide round the clock customer support

- Convenient online submission

- Thorough peer review

- Inclusion in PubMed and all major indexing services

- Maximum visibility for your research

Submit your manuscript at www.biomedcentral.com/submit 